\title{
Conflitos socioambientais na Costa Rica contemporânea
}

Alberto Gutiérrez Arguedas

RESUMO: O presente artigo tem como objetivo analisar o cenário atual de conflitos e lutas socioambientais na Costa Rica, relacionados ao controle, à apropriação e à gestão dos bens/recursos naturais e dos territórios onde estes se localizam. Classificam-se os conflitos em torno de sete eixos de conflitividade e aprofunda-se o estudo do eixo que corresponde às lutas comunitárias contra barragens hidrelétricas e em defesa dos rios, fenômeno que ganhou maior visibilidade e protagonismo a partir da década de 1990. O trabalho procura relacionar a especificidade da realidade costarriquenha com as características gerais desses processos na América Latina.

PALAVRAS-CHAVE:

Socioambientais. Costa Rica Bens/ Recursos Naturais. Barragens Hidrelétricas. Defesa Comunitária dos Territórios.

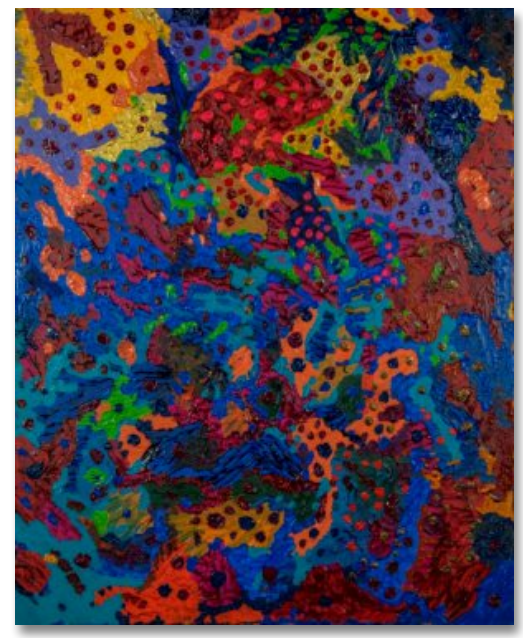

\section{socioenviromental conflicts in contemporary Costa Rica}

\section{Alberto Gutiérrez Arguedas}

Bacharel em Geografia pela Universidade de Costa Rica (UCR) e mestre em Geografia pela Universidade Federal do Rio Grande do Norte (UFRN). Professor e pesquisador no Departamento de Ciências Sociais da Sede Regional de Ocidente da UCR e no Centro de Investigación y Estudios Políticos (CIEP).

E-mail: alguar48@gmail.com
ABSTRACT: This article analyzes the current scenario of socioenvironmental conflicts and struggles in Costa Rica, related to the control, appropiation and management of natural goods/resources and the territories where they are located. Conflicts are classified around seven types, and emphasis is placed in one of them, the community struggles against hydroelectric dams and in defense of rivers, a phenomenon that gained greater visibility and prominence since the 1990s. The articule also seeks to relate the specificity of the Costa Rican context to the general characteristics of these processes in Latin America as a whole.

KEYWORDS: Socioenvironmental Conflicts. Costa Rica. Natural Goods/Resources. Hydroelectric Dams. Community Defense of Territories.

RECEBIDO EM: 01/02/2019

APROVADO EM: 20/07/2019 


\section{Introdução}

Na América Latina, nos últimos vinte anos, observam-se um aprofundamento e uma proliferação de conflitos e lutas sociais que, de uma forma ou de outra, estão relacionados ao controle, à apropriação e à gestão dos bens/recursos naturais e dos territórios onde estes se localizam. Esse tipo de conflito/luta, normalmente qualificado com o adjetivo "socioambiental", passou a ocupar um lugar de destaque na região e a conformar-se como um de seus principais eixos de antagonismo social. Como vem sendo destacado, o atual ciclo de conflitos socioambientais latino-americano se dá como resposta a um novo modelo de acumulação, implementado na região desde os anos 1990, segundo o qual se verifica uma intensificada exploração dos bens/recursos naturais, com graves consequências para os ecossistemas, as comunidades e seus modos de vida. A Costa Rica, um dos sete países da América Central, não escapa desta realidade, como tentará ser demonstrado ao longo desse trabalho.

Tendo em vista esse contexto, o presente artigo tem como objetivo analisar criticamente o cenário atual de conflitos e lutas socioambientais na Costa Rica, com ênfase em um dos seus principais eixos de conflitividade nas duas últimas décadas, a saber, as disputas suscitadas pela construção e/ou intenção de construir barragens hidrelétricas em diferentes rios do país. Desde meados dos anos 1990 até hoje, as lutas contra barragens ou em defesa dos rios, protagonizadas por dezenas de organizações e comunidades rurais costarriquenhas, ganharam maior visibilidade e se tornaram comuns no cenário político nacional. Aliás, essas lutas surgem em meio a um contexto mais amplo, de exacerbação dos conflitos socioambientais de forma geral, contraditoriamente, em um país que se vende ao mundo como um paraíso ecológico "sem ingredientes artificiais". ${ }^{1}$

O texto está organizado em três partes: na primeira, se faz uma discussão geral sobre os processos de conflito e luta socioambiental na Costa Rica, à luz do que vem acontecendo nesse campo na América Latina. Na segunda seção, se oferece uma tentativa de classificação em torno de sete eixos de conflitividade, para visualizar esses processos na sua inserção territorial concreta. Na terceira

1 "Costa Rica sem ingredientes artificiais" é um dos slogans oficiais do Instituto Costarricense de Turismo (ICT) para promover o país como destino turístico de alto valor ecológico e natural. 
parte, o foco da análise se coloca sobre as lutas em defesa dos rios, as quais se mobilizam frente à grave ameaça que representa, para as comunidades e os ecossistemas, a construção de barragens para geração de energia elétrica. As reflexões e informações reunidas neste artigo são, em parte, o resultado de um projeto de pesquisa desenvolvido entre 2017 e 2018 no Centro de Investigación y Estudios Políticos (CIEP) da Universidade da Costa Rica (UCR), cujo apoio financeiro e acadêmico foi indispensável para sua realização. ${ }^{2}$

\section{Conflitos e lutas socioambientais: breve caracterização}

Falar de conflitos e lutas socioambientais na Costa Rica implica colocar em questão o imaginário e o discurso oficiais em relação à sua gestão ambiental. Se por algum motivo é conhecido este pequeno país centro-americano no cenário mundial, é por causa de sua reputação como país comprometido com o "desenvolvimento sustentável", principalmente em duas áreas: conservação de ecossistemas naturais (abrangendo uma quarta parte do território nacional terrestre) e matriz de geração de eletricidade (baseada majoritariamente em fontes renováveis). Incontáveis representações, tanto no âmbito nacional quanto internacional, constantemente difundem esse imaginário, seja em publicidade turística, matérias jornalísticas, artigos acadêmicos e blogs de visitantes, seja em relatórios técnicos de ONGs, associando termos como "paraíso", "verde", "sustentável" e "natural" às descrições do país. Recentemente, um coletivo de cientistas sociais costarriquenhos(as) cunhou o termo "excepcionalismo verde", para fazer referência a esse conjunto de representações associadas à gestão ambiental do país. ${ }^{3}$ Nem tudo nesse imaginário é fictício, porém; é uma verdade parcial, que esconde as contradições e complexidades que envolvem as relações sociedade(s)-natureza.

2 Nome do projeto: "Conflictos socioambientales por represas y proyectos hidroeléctricos en Costa Rica, 2000-2015", inscrito na Vice-reitoria de Pesquisa da Universidade da Costa Rica, com o número B7347.

3 As reflexões em torno do "excepcionalismo verde" costarriquenho constituem o núcleo central do grupo de pesquisa Poder, Naturaleza y Territorio, vinculado ao CIEP da UCR. Nele participam os (as) pesquisadores (as) Andrés León, Alonso Ramírez, Tania Rodríguez, Maria José Guillén, José Mora e Alberto Gutiérrez. 
A mais evidente dessas contradições é o fato de que, a partir da década de 2000, verifica-se um aumento significativo dos conflitos sociais e ações de protesto relacionados com temáticas ambientais, dando-se uma multiplicação de disputas desse tipo em diferentes regiões do país, principalmente nos espaços rurais, nos quais se localizam a maior quantidade de bens/recursos naturais (LLAGUNO; MORA; PICADO, 2013). Essa asseveração é sustentada com dados empíricos, tais como os que fornecem o Instituto de Investigaciones Sociales (IIS) da Universidade da Costa Rica (UCR) e o Programa Estado de la Nación (PEN). Desde 1994, ambos os centros de pesquisa vêm fazendo um trabalho de monitoramento e sistematização das ações coletivas de protesto, cuja principal fonte de informação são alguns meios jornalísticos do país, os quais são revisados diariamente. ${ }^{4}$ A partir das bases de dados construídas ao longo de vinte anos, foi possível constatar o crescente peso das questões ambientais dentro do cenário geral das lutas sociais no país (PEN, 2014).

Os pesquisadores do PEN Chacón e Merino (2014), identificam uma série de características comuns à conflitividade ambiental como um todo nestes vinte anos. Chama a atenção o fato de que os principais atores que protagonizam essas lutas são grupos de vizinhança organizados (49,8\% dos casos registrados), os quais comumente agem no âmbito local e comunitário. Esses grupos têm mais protagonismo, inclusive, que as próprias organizações autoidentificadas como ambientalistas (26,9\% dos casos). No entanto, esse tipo de conflito, aparentemente circunscrito à escala local, muitas vezes ganha visibilidade em escala nacional e desperta o interesse da imprensa, das redes sociais e da sociedade em geral (CHACÓN; MERINO, 2014). Em muitos casos, as organizações locais de vizinhança não agem de forma isolada, senão que se articulam com uma diversidade de atores sociais e/ou institucionais aliados, muitos dos quais estão sediados nos espaços urbanos, principalmente em San José, capital do país.

4 Inicialmente, esse trabalho era realizado de forma conjunta entre ambos os centros de pesquisa; no entanto, a partir de 2010, cada um continuou o trabalho de forma independente. No caso do IIS da UCR, a base de dados de ações coletivas de protesta está disponível online, aliás, organizada em categorias, para facilitar as consultas. Cf. informações disponíveis em: <https://protestas. iis.ucr.ac.cr/>. Acesso em: 31 jul. 2019. 
Como já se mencionava na introdução, o aprofundamento e a multiplicação de conflitos socioambientais não são um fenômeno exclusivo de um país, mas sim de todo o subcontinente latino-americano, incluída a América Central. Não é por acaso que o estudo dos conflitos e das lutas socioambientais se tornou um dos campos mais férteis e dinâmicos dentro das ciências sociais, na América Latina, na última década. Mais do que um conjunto disperso de trabalhos e reflexões, ao redor dessa temática vem sendo construído um corpus teórico e metodológico relativamente coeso, uma ecologia política latino-americana, que tem como uma de suas características o vínculo entre as reflexões acadêmicas com os próprios processos de luta socioambiental.

De acordo com Composto e Navarro (2014), o atual ciclo latino-americano de conflitos socioambientais se dá como resultado da implementação de um novo modelo de acumulação no subcontinente, a partir da década de 1990, o qual corresponde, em termos gerais, com o projeto político-econômico e ideológico do Consenso de Washington. Nesse contexto, os territórios e bens/recursos naturais da América Latina adquirem renovado protagonismo como um dos núcleos centrais do desenvolvimento capitalista, dando como resultado uma intensificação e expansão de megaprojetos para o controle, a extração e a exportação de bens/recursos naturais (SVAMPA, 2013). Exemplos disso são uma agressiva expansão de monoculturas comerciais para a exportação, um novo ciclo mineiro na região, novos projetos - e novas formas - de extração de combustíveis fósseis (como o fracking), obras de infraestrutura para a circulação de matérias-primas e mercadorias (oleodutos, gasodutos, estradas, portos, aeroportos, hidrovias), assim como projetos para geração de energia, em que as barragens hidrelétricas ocupam um lugar importante, tendo em vista a enorme riqueza hídrica da região.

Segundo Alimonda (2008), o ajuste estrutural neoliberal na América Latina implicou uma profunda "reprimarização" de suas economias, trazendo consigo fortes impactos socioambientais. Os países latino-americanos, frente à crescente demanda de matérias-primas e bens de consumo nos países centrais e nas potências emergentes, pressionados pelos organismos financeiros 
internacionais para o pagamento da dívida externa (contraída em dólares), são forçados a intensificar a exploração e a exportação de bens/recursos naturais, aprofundando sua inserção periférica e em condição desvantajosa no sistema-mundo capitalista, como provedores de matérias-primas e commodities sem valor agregado. Para se ter noção da magnitude desse processo de espoliação, um exemplo: no México, já se extraiu sete vezes mais ouro desde a implementação do Tratado de Livre Comércio da América do Norte (TLCAN), em 1994, do que nos 300 anos do período colonial (PADIERNA, 2017)..

As fronteiras do mercado se expandem para espaços geográficos até então fora dos seus limites, incorporando-os aos circuitos de acumulação de capital. E como essa expansão não se dá sobre espaços vazios, mas sobre os territórios de vida de diferentes grupos humanos, a implementação do modelo implica a separação forçosa, e muitas vezes violenta, de seus meios de produção e reprodução da vida. Nas periferias do capitalismo neoliberal, a espoliação sobre os territórios e os bens/recursos naturais cumpre um papel fundamental nos processos de acumulação, exacerbando não somente a contradição capital-trabalho, mas também a "segunda contradição do capitalismo": capital-natureza, onde há uma estreita relação entre acumulação de capital e deterioro ambiental (COMPOSTO; NAVARRO, 2014).

Nesse contexto, numerosos processos de resistência popular se organizam contra a privatização, exploração, poluição e/ou destruição dos bens/recursos naturais por parte de projetos extrativos e de "desenvolvimento" impulsionados por Estados, empresas privadas e organismos multilaterais. Vários autores e autoras coincidem ao afirmar que, a partir dos anos 1990, se inaugura um novo/renovado ciclo de lutas sociais na América Latina, cujo denominador comum é a defesa dos territórios e dos bens/recursos naturais frente à ofensiva (neo)extrativista (SVAMPA, 2013; COMPOSTO; NAVARRO, 2014; MERLINSKY, 2018). A socióloga argentina Maristella Svampa (2013) cunhou o sugestivo termo de giro ecoterritorial ("virada ecoterritorial"), para denominar essa reconfiguração nas lutas sociais, nas quais emergem formas alternativas de participação e mobilização cidadãs e, junto com estas, 
um renovado repertório de alianças políticas, sensibilidades e linguagens, com forte protagonismo de comunidades indígenas e camponesas.

De acordo com Merlinsky (2018), podem identificar-se cinco características-chave nesses "novos movimentos socioambientais" na América Latina: (1) a inscrição territorial das lutas, nas quais os reclamos e as reivindicações estão em relação direta com o espaço geográfico habitado por cada grupo e, ao mesmo tempo, através das lutas se reforçam os laços sociais entre as pessoas e o território; (2) a resistência ao cerceamento e privatização dos bens comuns naturais, ou seja, dos elementos do meio ambiente que pertencem ao âmbito comunitário e cuja finalidade não está destinada para a produção de mercadorias, mas para a subsistência e reprodução da vida; (3) a produção de conhecimento coletivo, que surge como uma necessidade para visibilizar as problemáticas frente à negação e a indiferença das agências estatais, articulando de forma inovadora conhecimentos técnico-científicos com saberes populares-tradicionais; (4) a construção de espaços de deliberação e decisão autônomos e "autoconvocados", usualmente por fora dos espaços de representação política tradicionais, tais como os partidos e os sindicatos; e, finalmente; (5) a demanda pelo reconhecimento de direitos, aliás, direitos que ultrapassam a concepção liberal-individual e incorporam outras dimensões como os direitos coletivos e, inclusive, os direitos da natureza e dos seres não humanos.

No caso específico da Costa Rica, a exacerbação da conflitividade socioambiental nas últimas duas décadas reflete uma importante tensão entre o discurso oficial que apresenta o país como um paraíso ecológico e uma crescente e aberta interpelação daquele discurso por parte de diversos atores sociais, deixando em evidência uma "dupla moral" do país em matéria ambiental (MONGE, 2014). De acordo com Monge (2014), cujo trabalho analisa as lutas socioambientais na Costa Rica à luz das vivências e experiências subjetivas de um grupo de pessoas ativistas, muitos dos que se engajam nesse tipo de luta iniciam sua trajetória política como resposta a ameaças concretas contra suas vidas e suas comunidades por parte de atividades extrativas e megaprojetos; no entanto, 
nesse mesmo processo, terminam "formando-se e transformando-se" (MONGE, 2014, [s.p.]), compreendendo que existe um panorama geral de espoliação e conflitividade que transcende seu caso específico. Dessa forma, muitos(as) dos(as) ativistas socioambientais e das lutas nas quais participam questionam a ideia em si de desenvolvimento e constroem argumentos e visões de mundo contra-hegemônicas, as quais concebem o bem-estar e a qualidade de vida para além de indicadores econômicos.

\section{Eixos de conflitividade socioambiental}

De forma preliminar, poder-se-ia classificar o cenário atual de lutas socioambientais na Costa Rica em torno de sete eixos de conflitividade, os quais estão definidos em função do tipo de atividade que os gera. Cada um desses eixos tem características específicas no que tange aos impactos ou às ameaças provocadas por essas atividades, assim como às reivindicações e às estratégias de resistência por parte dos atores sociais. Os sete eixos são: (1) expansão de monoculturas de exportação; (2) enclaves turísticos e novas urbanizações; (3) superexploração d'água para projetos de irrigação; (4) infraestruturas de transporte; (5) mineração a céu aberto; (6) recuperações de terra em territórios indígenas; e (7) barragens hidrelétricas.

Ao mesmo tempo, existem importantes semelhanças e pontos em comum que atravessam os diferentes eixos, dentre os quais vale a pena fazer ênfase num aspecto fundamental. Da mesma forma que aconteceu na maioria dos países da América Latina, as décadas de 1980 e 1990 na Costa Rica marcaram um ponto de inflexão na trajetória do país, com a ascensão e a consolidação do neoliberalismo. Para poder cumprir suas obrigações com os organismos financeiros internacionais, a Costa Rica assinou três Programas de Ajuste Estruturais (PAEs) ${ }^{5}$ nos quais se comprometia a assumir uma série de medidas para garantir a estabilização macroeconômica e o pagamento da dívida externa. De forma geral, tais medidas visavam a uma maior abertura da economia

5 PAE I, em 1985; PAE II, em 1989; e PAE III, em 1995. 
nacional aos circuitos de acumulação transnacionais, através da liberalização comercial (estímulo às exportações e ao investimento estrangeiro direto), à privatização de empresas e serviços públicos, à flexibilização (precarização?) do mercado de trabalho e à financeirização da economia (LEÓN, 2015). Como se verá, muitos dos conflitos socioambientais, de uma forma ou de outra, guardam relação com este modelo de desenvolvimento que acelera a pressão exportadora sobre os bens/recursos naturais, provocando espoliação com uma velocidade e uma intensidade inusitadas.

Na sequência, uma breve descrição de seis dos sete eixos de conflitividade socioambiental na Costa Rica contemporânea. O sétimo eixo será discutido em seção posterior. Trata-se de um esforço de classificação inicial, que está longe de ser exaustivo e pode ser ampliado e melhorado.

\subsection{Expansão de monoculturas de exportação}

O setor agrário foi um dos mais severamente impactados pelo ajuste estrutural dos anos 1980 e 1990. Apesar de ser um país historicamente agroexportador, a implementação de uma série de medidas neste setor, com a intenção explicita de promover as monoculturas comerciais de exportação, veio provocar significativos impactos territoriais e socioeconômicos nos espaços rurais, aprofundando a dependência histórica do país em relação ao mercado mundial. Estimula-se fortemente (através de isenções fiscais, por exemplo) o investimento nos chamados produtos não tradicionais, a maioria controlados por capital transnacional abacaxi, palma africana, laranja e melão -, dentre outros, além de produtos tradicionais de exportação, como a banana e a cana-de-açúcar, em detrimento da produção de grãos básicos (arroz, feijão e milho) e tubérculos para o mercado local e o autoconsumo das famílias camponesas.

A expansão de algumas dessas monoculturas aconteceu de forma muito acelerada e agressiva, provocando graves impactos socioambientais, com destaque para o abacaxi, cuja extensão territorial aumentou em torno de 700\%, entre 1990 e 2010 (LLAGUNO et al. , 2014). De fato, a Costa Rica tornou-se o exportador número um 
desse produto em nível mundial. De acordo com os(as) autores(as) citados(as), algumas das principais problemáticas associadas a esta monocultura são: a eliminação de práticas agrícolas tradicionais (e, por consequência, da soberania alimentar do país); a concentração de terras em mãos de grandes corporações; problemas na saúde da população, devido às constantes fumigações sobre as plantações e à exposição direta dos trabalhadores a substâncias tóxicas; a contaminação dos rios e águas subterrâneas por causa dos agrotóxicos; desmatamento e perda de biodiversidade; aumento na sedimentação dos rios, lagoas e pântanos por causa da erosão dos solos; e o desrespeito sistemático aos direitos e garantias laborais dos trabalhadores, muitos deles migrantes empobrecidos da Nicarágua.

Diante desse cenário, muitas comunidades afetadas pela expansão das monoculturas de abacaxi se organizaram e se mobilizaram para denunciar os graves impactos provocados por esse modelo de exportação, principalmente nas regiões Norte, do Caribe e do Pacífico-Sul, assim como para exigir o respeito aos seus direitos fundamentais (dentre eles, o direito à saúde, ao trabalho decente e a um meio ambiente equilibrado, consagrados na Constituição). Desde estas comunidades e desde o movimento ecologista, se propõe uma moratória nacional à expansão das plantações de abacaxi, ou seja, que não se concedam novas licenças para esse tipo de atividade. As diferentes organizações comunitárias estão articuladas em torno da Frente Nacional de Sectores Afectados por la Producción Piñera (FRENASAPP) ${ }^{6}$.

\subsection{Enclaves turísticos e novas urbanizações}

Outro setor estratégico dentro do modelo de acumulação neoliberal é o turismo. Com particular intensidade no litoral PacíficoNorte do país, na província de Guanacaste, estabeleceu-se um

6 Os abusos provocados pelas monoculturas de abacaxi na Costa Rica já receberam fortes críticas e denúncias, inclusive em nível internacional. Dois dos principais meios de comunicação críticos da Europa realizaram reportagens mostrando os graves impactos socioambientais dessa indústria. Cf. PIÑAS... (2010) e COSTA... ([s.f.]). 
conjunto de polos ou enclaves turísticos, caracterizado pelas grandes dimensões dos empreendimentos (turismo de massa) e pela predominância do capital transnacional (grandes cadeias hoteleiras). A criação de um aeroporto internacional nessa província em 1995 (o segundo em todo o país) foi determinante para a consolidação do modelo. O estabelecimento desses polos turísticos associa-se a um crescimento vertiginoso do setor imobiliário e do espaço construído, assim como à privatização das praias e a um uso intensivo do recurso hídrico, sobretudo de águas subterrâneas (aquíferos).

Nesse eixo, o detonante dos conflitos tem sido a questão do acesso à água. A crescente demanda deste bem/recurso natural por parte dos hotéis e do turismo residencial (em alguns casos para finalidades banais, como piscinas e campos de golfe $)^{7}$ atenta diretamente contra o abastecimento d'água para muitas comunidades, com o agravante de que Guanacaste é a região do país com a estação seca mais prolongada (de 5 a 6 meses). O caso mais conhecido é o da comunidade de Sardinal, que, desde 2007, luta contra a construção de um aqueduto que pretende aumentar o volume d'água a ser extraído do aquífero que abastece a população, para ser levada a um dos principais núcleos turísticos, nas praias de El Coco e Ocotal. Para além desse caso particular, os conflitos hídricos atravessam a província de Guanacaste, como revela o trabalho de Ramírez (2007), ao registrar um total de 65 disputas desse tipo, entre 1997 e 2006.

Fora dos enclaves turísticos, também se registram conflitos relacionados com o acesso à água em áreas onde pretende-se realizar projetos urbanísticos, principalmente nas periferias da Grande Área Metropolitana de San José, cidade cercada por montanhas com ricas reservas d'água.

7 De acordo com Lawrence Pratt, professor da escola de negócios INCAE, um campo de golfe consome, na média, a mesma quantidade de água que uma comunidade dentre 5.000 e 10.000 pessoas (QUEBRANDO..., 2013). 


\subsection{Superexploração d'água para projetos de irrigação}

Esse eixo guarda estreita relação com o anterior, porém, apresenta algumas características próprias. Uma delas é que, à diferença dos conflitos associados aos enclaves turísticos e às novas urbanizações, neste caso, trata-se da exploração de águas superficiais, ou seja, dos rios, principalmente para uso agropecuário. A problemática concentra-se nas regiões Pacífico-Central e PacíficoNorte, onde a exploração desmedida dos rios faz com que alguns deles fiquem quase sem água durante a estação seca. Destaca-se o caso da comunidade de Guacimal, que, entre 2011 e 2016, protagonizou uma forte luta contra um projeto que pretendia extrair 90\% das águas do rio que atravessa a comunidade, para ser usada em fazendas de gado e nas plantações de abacaxi. Guacimal, em conjunto com outras comunidades rurais vizinhas que enfrentam problemáticas/ameaças similares, se organizaram em torno de uma plataforma regional chamada Alianza por la Defensa del Recurso Hídrico en el Cantón Central de Puntarenas, cuja luta vai para além desse projeto específico e busca incidir na construção de uma nova legislação em matéria de recursos hídricos no país, que atualmente permite outorgar para concessão até 90\% das águas dos rios para sua exploração particular (VILLALOBOS, 2018).

\subsection{Infraestruturas de transporte}

São elementos fundamentais dentro da dinâmica geral do desenvolvimentismo extrativista, funcionando como as vias através das quais circulam matérias-primas, mercadorias e pessoas. Aliás, a instalação desse tipo de obra pode ser, em si mesma, uma forma de espoliação sobre populações e territórios. Dois casos merecem destaque, cada um com desenlaces diferentes:

- Aeroporto Internacional do Sul: a partir de 2010, se tornou pública a intenção do governo de construir um terceiro aeroporto internacional no país, na região Pacífico-Sul, com o propósito de estimular o crescimento do turismo (ao mesmo estilo que Guanacaste). Diversos setores colocaram resistência ao projeto, dentre eles as comunidades 
camponesas de Finca 9 e Finca 10, as quais habitam o mesmo local onde seria construído o aeroporto e manifestam seu desejo de continuar morando nesse lugar e mantendo seu modo de vida ligado diretamente com a terra (MORA, 2015). ${ }^{8}$ Outro argumento contra a construção do aeroporto é a afetação direta que teria sobre um sítio arqueológico pré-hispânico, declarado patrimônio mundial da humanidade pela Organização das Nações Unidas para a Educação, a Ciência e a Cultura (UNESCO), em 2014. O projeto encontra-se parado, por enquanto.

- Terminal de Contêineres de Moín: o porto de Moín, localizado no litoral do Caribe, é um ponto geoestratégico, sendo o porto através do qual circula aproximadamente 80\% do comércio internacional do país. Em 2010, o governo da Costa Rica privatizou a atividade portuária, através de uma concessão outorgada a uma empresa holandesa (APM Terminals) para construir e operar um novo terminal de contêineres em Moín, que entrou em funcionamento em 2019. Vários setores manifestaram oposição à privatização do porto e à construção do novo terminal de contêineres, dentre eles o sindicato de trabalhadores portuários da empresa pública (dimensão trabalhista do conflito) e os grupos ambientalistas. Esses movimentos de oposição consideraram os fortes impactos provocados pela construção do megaporto, localizado numa das principais praias onde ocorre a desova de tartaruga marinha em todo o litoral do Caribe, a qual é de altíssima importância ecológica.

\subsection{Mineração a céu aberto}

Apesar de a Costa Rica não ser um país com uma forte tradição em mineração, no passado, já teve experiências desse tipo de atividade e é justamente nesse eixo que se deu um dos principais conflitos

8 O documentário Botas con Machete, do cineasta Alejandro Ferlini, mostra o cotidiano das comunidades camponesas de Finca 9 e Finca 10, assim como os motivos pelos quais os moradores se opõem à construção de um aeroporto internacional nesse lugar. Cf. BOTAS... (2012). 
socioambientais da última década, de ampla repercussão nacional e internacional. O projeto mineiro Crucitas, localizado no município de San Carlos, na região Norte perto da fronteira com a Nicarágua, era um megaprojeto de mineração de ouro a céu aberto, pertencente à empresa canadense Infinito Gold. O projeto recebeu apoio do governo de Óscar Arias, que, em 2010, assinou um decreto de interesse público e conveniência nacional para agilizar as gestões. No entanto, conformou-se um bloco opositor muito forte, com participação de comunidades vizinhas, grupos ecologistas, ONGs e alguns setores da academia, os quais conseguiram incidir significativamente na opinião pública e modificar o balanço de forças contra o projeto (pesquisas de opinião revelaram, naquele momento, uma oposição de $90 \%$ da população do país). A tensão foi aumentando e atingiu seu pico quando um grupo de pessoas montou um acampamento frente à Casa Presidencial e manteve uma greve de fome durante 26 dias, entre outubro e novembro de 2010. Nesse mesmo ano, um Tribunal Contencioso Administrativo ordenou anular a concessão e, posteriormente, se aprovou no Congresso uma lei que proíbe a mineração a céu aberto em todo o país. ${ }^{9}$

\subsection{Recuperações de terra em territórios indígenas}

De forma geral, existe uma grave problemática nos territórios indígenas da Costa Rica em relação à posse das terras. Apesar de a Lei Indígena de 1977 estabelecer os territórios indígenas como de uso exclusivo desses povos (total de 24 territórios demarcados em todo o país, ocupados por 8 grupos étnicos), na prática, mais da metade das terras dentro desses territórios estão em mãos de pessoas não indígenas, que, ao longo do tempo, as apropriaram de forma ilegítima, violentando flagrantemente as leis nacionais e os convénios internacionais nessa matéria. Frente a este cenário, à negligência e à inação crônicas do Estado para corrigir o problema, a partir de 2010, observa-se uma mudança na estratégia de luta das comunidades indígenas costarriquenhas, as quais, em vez de continuar indo à capital para negociar infrutuosamente com

9 Para aprofundar no caso do projeto de mineração Crucitas, se recomenda consultar o documentário El Oro de los Tontos. Cf EL ORO... (2011). 
as instituições para o cumprimento dos seus direitos territoriais, optaram por "recuperar as terras com as próprias mãos".

Concretamente, uma recuperação de terra consiste numa ocupação coletiva por parte das pessoas indígenas (com participação de mulheres, homens, jovens, crianças e idosos) daquelas fazendas que estão em mãos dos não indígenas. Nesses lugares, essas pessoas montam um acampamento e passam a morar e trabalhar nessas terras, recuperando os territórios na prática, no dia a dia. Esse fenômeno acontece, sobretudo, em vários territórios indígenas da região Sul do país, tais como Salitre, Cabagra e Térraba (os dois primeiros do grupo étnico Bribri e o terceiro do grupo Bröran), nos quais, depois de vários anos desde o início das ocupações, já se observa uma reconfiguração na estrutura da posse das terras (CICDE, 2018).

A parte ambiental entra quando se vê que, naquelas terras recuperadas pelos indígenas, os pastos degradados e improdutivos vão sendo substituídos, aos poucos, pelo verde das florestas e dos roçados, assim como as fontes de água, que por muitos anos ficaram secas pelo desmatamento, começam a brotar novamente. Para eles e elas, recuperar o território é recuperar sua cultura e também a natureza. Infelizmente, a repressão e a violência racistas dos fazendeiros têm sido uma constante, desde que iniciaram as recuperações. Reportam-se graves ataques (físicos e psicológicos) e violações aos direitos humanos, reconhecidos inclusive pela Comissão Interamericana dos Direitos Humanos (CIDH), que, em 2015, solicitou ao Estado da Costa Rica medidas de proteção (medidas cautelares), para garantir a vida das populações indígenas. O conflito está em aberto. ${ }^{10}$

A próxima seção do artigo consistirá de uma análise mais detalhada do eixo de conflitividade das barragens hidrelétricas.

10 No dia 18 de março de 2019, a violencia contra os recuperadores de terra indígenas atingiu um novo e dramático patamar com o assassinato do principal líder do movimiento, Sergio Rojas Ortiz, indígena da etnia Bribri e morador do territorio de Salitre. Ele recebeu 13 disparos de arma de fogo, dentro de sua própria casa. Para mais informações, consultar Gutiérrez Arguedas (2019). 


\section{As lutas em defesa dos rios contra barragens hidrelétricas}

A Costa Rica é um país com grande riqueza hídrica. Localizado na faixa tropical do planeta, recebe abundantes precipitações em todo ou em parte do ano, dando como resultado uma ampla presença de rios e corpos d'água em geral. Associado a isso, o sistema montanhoso central que atravessa o país do noroeste ao sudeste, como uma coluna vertebral, faz com que muitos desses rios caiam com força sobre encostas íngremes. Ambos os fatores (abundância d'água e topografia acidentada) proporcionam as condições ótimas para a exploração hidrelétrica, o que explica (em parte) por que a matriz de geração de energia elétrica no país está baseada majoritariamente em fontes hídricas, desde que iniciou esta atividade no final do século XIX até hoje. Atualmente, quase 3/4 (ou 71\%) da capacidade de geração elétrica instalada na Costa Rica é proporcionada pelas barragens hidrelétricas (ICE, 2017).

Durante mais de quatro décadas, a geração elétrica no país foi de competência exclusiva do Estado, através do Instituto Costarricense de Electricidad (ICE). O ICE foi criado em 1949, com a intenção de nacionalizar um dos setores mais estratégicos da vida nacional, como é o setor elétrico, tornando-se uma instituição-chave dentro do modelo de Estado benfeitor-desenvolvimentista que predominou entre as décadas de 1950 e 1980. Nesse período, experimentou-se uma espetacular expansão do setor elétrico, materializada através da construção de um conjunto de grandes barragens (existentes até hoje) e de uma infraestrutura elétrica associada (linhas de transmissão e distribuição, etc.). Prova dessa expansão é o fato que a porcentagem da população costarriquenha com acesso à energia elétrica aumentou exponencialmente, durante a segunda metade do século XX - de 14\%, em 1949, a 97\% em 2000, alcançando atualmente um total de 99,4\% (ICE, 2017).

Em contrapartida, a década de 1990 marca um ponto de inflexão com a incursão de empresas privadas na geração elétrica, conformando uma espécie de modelo "misto", em que coexistem empresas públicas e privadas. Essa mudança foi realizada através de duas leis conhecidas como leis de cogeração (leyes de cogeneración): primeiro, a lei 7.200 de 1990 e, posteriormente, a lei 7.508 
de 1995. ${ }^{11}$ Elas autorizaram a geração de energia elétrica por parte de empresas privadas, através de um esquema conhecido como cogeração ou geração elétrica paralela, no qual se estabelece que o Estado (através do ICE) está na obrigação de comprar toda a eletricidade produzida em usinas privadas, para posteriormente distribui-la aos usuários. Esse aspecto, dentre outros, fez com que estas leis recebessem fortes críticas por terem montado um "negócio milionário" privado, a partir de fundos públicos e da exploração de um bem comum como são os rios, modificando o marco regulatório em favor de claros interesses particulares (FECON, 2003a).

As leis de cogeração devem ser lidas como parte de um processo de maiores dimensões, isto é, a (tentativa de) privatização do setor elétrico de forma geral. Nesse sentido, é preciso fazer referência a um projeto de lei promovido pelo governo da Costa Rica, no final dos anos 1990, conhecido popularmente como o "Combo do ICE", que pretendia privatizar completamente os serviços de energia e telecomunicações. O "Combo" provocou uma das maiores mobilizações populares da história recente do país, sendo finalmente retirado do Congresso, em março de 2000, devido à forte pressão do movimento ambientalista. De acordo com Solís (2002), a derrota que sofreu a elite nas ruas em 2000 a obrigou a desistir de qualquer tentativa privatizadora abrupta e continuar no caminho de uma privatização "gradual e progressiva", iniciada com as leis de cogeração.

No contexto da luta contra o "Combo", o setor elétrico politizou-se como nunca antes e foram levantados questionamentos ao modelo elétrico em si, para além daquele projeto de lei em específico (FECON, 2003a). Aliás, embora a luta tenha girado em torno da tensão entre uma gestão pública ou privada do setor elétrico, o conflito esteve também marcado por tensões de

11 As leis 7200 e 7508 são essencialmente a mesma. A segunda dessas leis veio modificar e reformar uma série de aspectos pontuais da primeira, em direção a uma maior participação do setor privado na geração elétrica. Na lei 7200, a geração elétrica privada não podia superar $15 \%$ da oferta elétrica total do país, as usinas pertencentes a essas empresas não podiam ser maiores a $20 \mathrm{MW}$ e as concessões tinham 15 anos de vigência. Na lei 7508, esses limites aumentam a 30\%, 50 MW e 20 anos, respectivamente. 
tipo socioambiental, considerando que a aprovação do projeto de lei teria implicado uma forte desregulação e, por consequência, uma maior exploração dos rios com fins de geração elétrica (CARTAGENA, 2010). O autor citado informa que o movimento ambientalista teve uma participação importante na luta contra o "Combo", com destaque para a Federación Costarricense para la Conservación de la Naturaleza (FECON), assim como várias organizações locais de base comunitária. Naquela época, se conformou o Grupo de Trabalho Energia dentro da FECON, um espaço de reflexão crítica sobre a geração privada de eletricidade e o modelo elétrico em geral, o qual se tornaria um espaço fundamental não só de investigação e denúncia dos abusos da cogeração e dos impactos provocados pelas barragens, mas também de articulação das comunidades afetadas e/ou ameaçadas por esse tipo de projeto (FECON, 2003a; FECON, 2003b).

A liberalização do setor elétrico na década de 1990 abriu um novo nicho de negócios que foi rapidamente aproveitado por um conjunto de empresas privadas. Tendo isso em vista, uma das consequências mais evidentes provocadas por essa liberalização foi uma proliferação de barragens em dezenas de rios do país, num período de tempo relativamente curto. Assim, do total de 60 usinas hidrelétricas atualmente em funcionamento no país, só existiam 14 antes de 1990, enquanto, entre 1990 e 1999, foram construídas 22 novas barragens, o que corresponde a uma média de mais de duas por ano. Nas décadas seguintes, o boom hidrelétrico continuou, no entanto, o ritmo de construção de novas barragens diminuiu levemente (11 entre 2000 e 2009 e 13 desde 2010 até o presente). Nem todos os novos projetos pertencem a empresas privadas, no entanto, a correlação entre a implementação das leis de cogeração e o aumento acelerado no número de usinas é nítido. Na sequência, pode-se apreciar um mapa que mostra a distribuição geográfica das usinas hidrelétricas atualmente em funcionamento, classificadas em função da potência instalada: 
Mapa 1 - Usinas hidrelétricas em operação na Costa Rica

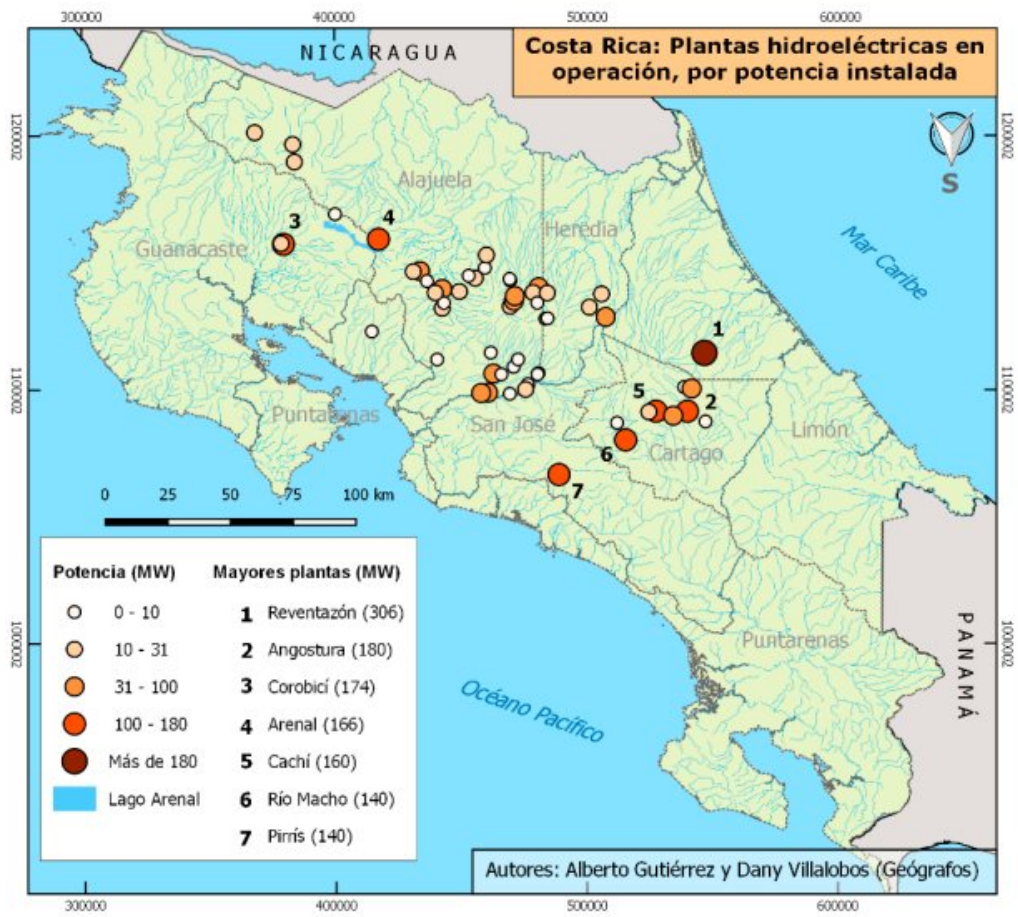

Fonte: Elaborado pelo autor, a partir de pesquisa documental e trabalho de campo realizado em 2018.

A acelerada expansão do setor hidrelétrico, experimentada a partir da década de 1990, atingiu de forma severa algumas regiões em específico, em cujos rios foram construídas até três ou quatro barragens por curso d'água. Inclusive, desde as próprias organizações ecologistas e comunitárias em defesa dos rios, surgiu o termo "enxames de barragens" (enjambres de represas), para fazer referência a essas regiões onde se deu uma maior concentração de projetos hidrelétricos, cujos impactos se manifestam de forma cumulativa, considerando que as usinas estão localizadas dentro do mesmo rio ou bacia hidrográfica (Mauricio Álvarez, em comunicação pessoal de 18 de janeiro de 2017, em San José, Costa Rica). Vale destacar o caso da bacia do rio San Carlos, localizado na região norte do país, com 15 usinas hidrelétricas em operação, 
a maioria destas como parte do boom pós-1990. Em palavras do dirigente comunitário de La Tigra de San Carlos, Otto Méndez, em entrevista concedida em 17 de outubro de 2017, "foi rápido, como um câncer, e quando percebemos, o desastre já estava feito".

A emergência das lutas socioambientais em defesa dos rios pode ser interpretada como uma resposta à expansão hidrelétrica acelerada e agressiva que se experimentou no país, a partir dos anos 1990. Embora tenham existido alguns casos de resistência contra barragens em outras épocas, ${ }^{12}$ a sistematização dos diferentes casos de conflito revela um ponto de inflexão, a partir da segunda metade da década de 1990, momento em que se verifica um aumento significativo na ocorrência desse tipo de disputa, amplamente distribuída por diferentes regiões do país. As lutas contra barragens se tornam comuns no cenário político nacional e ganham maior visibilidade, contribuindo para modificar, pelo menos parcialmente, a percepção social sobre as barragens e a geração de energia hidrelétrica, símbolos por excelência de prestígio, modernização e progresso tecnológico nacional.

Os diferentes processos de luta comunitária contra barragens que já existiam nos anos 1990, naquele momento com pouca articulação entre si, começam a se encontrar e construir espaços organizativos em comum. Assim, em 2001, inaugura-se uma nova etapa político-organizativa nas lutas em defesa dos rios, com a realização do I Fórum Nacional Barragens Hidrelétricas e Comunidades, organizado pelo Grupo de Trabalho Energia da FECON (FECON, 2003b). Pela primeira vez, membros de comunidades afetadas e/ ou ameaçadas por barragens hidrelétricas, provenientes de diferentes regiões do país, tiveram a oportunidade de encontrar-se e compartilhar as situações que estavam vivendo em relação à exploração dos rios para a geração de energia elétrica. Em 2003, se realiza o segundo encontro desse tipo, sob o nome de II Fórum Nacional de Comunidades Frente à Expansão Hidrelétrica, também organizado pela FECON, fortalecendo e consolidando o processo de articulação iniciado no primeiro encontro. O principal objetivo

12 Destaque para a luta dos povos indígenas da região sul do país contra o (mega)projeto hidrelétrico Boruca, do ICE, desde a década de 1960. 
desse espaço, tal como consta numa publicação escrita, foi o de "promover o encontro e estimular o desenvolvimento de um movimento nacional de comunidades afetadas negativamente pela expansão hidrelétrica" (FECON, 2003b, p. 02 - tradução própria).

Percebe-se uma mudança de escala muito interessante na luta contra barragens, segundo a qual problemáticas que eram consideradas locais adquirem caráter nacional, reconfigurando o balanço de forças nesses conflitos. Ao compartilhar experiências e conhecimentos, as pessoas entendem que não se trata de problemáticas isoladas e sem relação entre si, mas de um modelo de desenvolvimento que ameaça todos os rios e as comunidades por igual (FECON, 2003b). Assim, começava a tomar forma um movimento social contra barragens/em defesa dos rios, conformado por uma rede de dezenas de organizações comunitárias e ecologistas de abrangência nacional.

No entanto, na Costa Rica, não se tem constituído um movimento ou organização específica que reúna as diferentes resistências comunitárias em defesa dos rios em escala nacional, como existe, por exemplo, no Brasil e no México, com o Movimento de Atingidos por Barragens (MAB) e o Movimiento Mexicano de Afectados por las Presas y en Defensa de los Ríos (MAPDER), respectivamente. Na prática, existe um movimento social contra barragens/em defesa dos rios em escala nacional, mas trata-se de um movimento sem coordenação centralizada, formado a partir das articulações concretas e específicas entre as diferentes organizações de base comunitária. De acordo com o sociólogo e ativista Osvaldo Durán, em comunicação pessoal de 06 de agosto de 2017, em El Jardín de Dota, Costa Rica, a expressão básica deste movimento tem sido, em momentos determinados e conjunturas particulares, juntar as pessoas das diferentes comunidades para que todos e todas possam discutir, refletir e tomar decisões de forma conjunta. Nesse sentido, a realização de encontros, reuniões, fóruns, festivais, etc. tem sido fundamental dentro do repertório de ações de luta do movimento.

Hoje, quase vinte anos depois do primeiro encontro nacional, o movimento em defesa dos rios costarriquenhos não só conseguiu se manter ativo (com altos e baixos), mas também foi crescendo, 
incorporando novas organizações e comunidades e acumulando notável experiência e aprendizagem política. O movimento, aliás, possui também conexões em nível internacional, dentre as quais destacam-se a Rede Latino-americana Contra Barragens e em Defesa dos Rios, as Comunidades e a Água (REDLAR) e o Movimento Rios Vivos, plataformas organizativas supranacionais, nas quais vários ativistas e organizações da Costa Rica têm participação ativa. De fato, o sexto encontro da Rede Mesoamericana Contra Barragens (vinculada à REDLAR) foi realizado na comunidade de Pacuare, na Costa Rica, em setembro de 2011, com participação de umas 240 pessoas provenientes de mais de dez países (DURÁN, 2012).

A união entre diferentes comunidades, além de proporcionar um sentimento de solidariedade e ajuda mútua, permitiu que as pessoas tivessem maior acesso à informação relacionada com os projetos hidrelétricos e seus possíveis impactos socioambientais. Nesse sentido, as comunidades previamente afetadas por barragens serviram como exemplo e testemunho vivo para mostrar os danos irreversíveis provocados por esse tipo de obra, aspecto que tem sido crucial para gerar consciência crítica e conformar resistência frente a novos projetos. Para mencionar um exemplo, de acordo com a memória de luta da Comisión Defensora de los Ríos Convento y Sonador (2016), foi através de uma visita à região de San Carlos, principal "enxame hidrelétrico" no país, que visualizaram "ao vivo" a destruição que provocam as barragens, o que os levou a trabalhar para impedir que acontecesse a mesma coisa nos seus rios, na região sul do país. As comunidades se apropriaram de uma série de ferramentas para documentar e visibilizar as problemáticas relacionadas com o represamento dos rios (fotografias, vídeos, apresentações, depoimentos, etc.), tornando-se, elas mesmas, agentes de construção de conhecimentos e de um discurso contra-hegemônico em relação com a hidroeletricidade.

Da mesma forma, as comunidades organizadas desenvolveram capacidades de diálogo e negociação com o poder público e as empresas privadas exigindo, por exemplo, a realização de audiências públicas e outros espaços onde possam expor seus pontos de vista e serem levados em consideração. Nesse sentido, um dos fundamentos ético-políticos reivindicados por este movimento é o 
que se conhece como soberania comunitária, isto é, o direito das comunidades a decidir sobre um assunto que lhes afeta de forma direta (Osvaldo Durán, em comunicação pessoal de 06 de agosto de 2017, em El Jardín de Dota, Costa Rica). O acesso à informação relacionada com os projetos constitui um requisito indispensável no exercício da soberania comunitária, pois, caso contrário, as comunidades ficam totalmente excluídas do processo de tomada de decisões, como tinha sido o costume até recentemente. De acordo com Osvaldo Durán, em comunicação pessoal de 06 de agosto de 2017, em El Jardín de Dota, Costa Rica, as empresas públicas e privadas, que em outras épocas eram "recebidas de braços abertos" nas comunidades, agora passam a enfrentar grandes dificuldades para realizar seus projetos, pois se deparam com comunidades muito mais informadas e politizadas sobre o assunto.

A quantidade de casos de luta contra barragens, nos últimos vinte anos, na Costa Rica, é ampla; registram-se várias dezenas de casos, distribuídos por diferentes regiões do país, abrangendo uma grande diversidade de espaços geográficos e socioculturais. O que todas essas lutas têm em comum é o desejo das comunidades de defender e proteger um dos bens comuns naturais mais preciosos, como são os rios, frente a uma intervenção que é considerada uma ameaça e uma agressão, seja por parte de empresas privadas, seja de instituições públicas, como o ICE. Para estas comunidades, o rio é um elemento central da vida cotidiana, servindo não só como fonte d'água para diferentes finalidades (uso doméstico, agrícola, pecuário, para a pesca, o lazer e o turismo rural), mas como espaço ao redor do qual se constrói a vida comunitária, articulador das relações sociais e elemento de identificação com forte enraizamento territorial. Em alguns casos, como nos dos povos indígenas, o rio é uma entidade sagrada, a qual deve ser respeitada e venerada.

No marco do projeto de pesquisa desenvolvido no CIEP-UCR, se realizou uma sistematização dos diferentes casos de conflito por barragens na Costa Rica, cujos resultados são reveladores. Identificou-se um total de 35 projetos hidrelétricos que pretendiam ser construídos, mas que foram parados e/ou arquivados devido à resistência organizada das comunidades. Isso significa que, se não fosse por essa resistência, na Costa Rica teríamos atualmente em 
torno de 100 barragens, um número muito elevado para as dimensões do país (de 51.100 km² e 5 milhões de habitantes). Os projetos hidrelétricos parados e/ou arquivados pelo movimento social são o indicador mais claro da existência dessas lutas em defesa dos rios, assim como da sua eficácia e habilidade política. No entanto, o fato de os projetos estarem parados não significa que estejam sepultados em definitivo, pois, em alguns casos, estes podem ser reativados em qualquer momento.

A partir do levantamento e georreferenciamento dos projetos parados/arquivados por resistências comunitárias, foram identificados doze núcleos de resistência: (1) Upala, (2) San Carlos-San Ramón, (3) Sarapiquí, (4) Guácimo, (5) Coronado, (6) Acosta, (7) Naranjo-Savegre, (8) Pacuare-Duchí, (9) Pérez Zeledón-Buenos Aires, (10) Coto Brus, (11), Boruca-Diquís e (12) Talamanca. Em alguns casos, trata-se da resistência contra um único projeto, enquanto, em outros, trata-se de um conglomerado de barragens. Atualmente, o principal foco de conflitividade por barragens na Costa Rica localiza-se na região sul do país, especificamente nos municípios de Pérez Zeledón e Buenos Aires, onde existe a intenção por parte de várias empresas privadas de instalar 14 projetos hidrelétricos novos (ÁLVAREZ, 2013), dos quais até hoje não conseguiram construir nem sequer um, devido à forte resistência das comunidades locais. O mapa a seguir mostra a configuração geográfica das lutas em defesa dos rios contra barragens hidrelétricas na Costa Rica, deixando em evidência a forte tensão que existe no país em torno da apropriação e do uso dos bens/recursos naturais, nesse caso, dos rios. Os projetos parados/arquivados por resistências comunitárias estão representados em azul, enquanto as usinas em funcionamento, em laranja: ${ }^{13}$

13 Para visualizar as lutas em defesa dos rios na Costa Rica e seus protagonistas, recomendam-se dois trabalhos audiovisuais de grande qualidade técnica e didática: (1) o documentário Matar un Río, que mostra o conflito em torno do projeto hidrelétrico El Diquís, o de maior repercussão na opinião pública, recentemente (novembro 2018) arquivado pelo ICE, e (2) uma edição do programa de televisão Era Verde titulada A 10 años del plebiscito, iPacuare es vida! , que documenta um encontro nacional de comunidades realizado em 2015 , oferecendo uma perspectiva bastante esclarecedora do movimento em defesa dos rios e sua dinâmica organizativa. Ambos estão disponíveis no Youtube. 
Mapa 2 - Resistências comunitárias contra barragens hidrelétricas na Costa Rica

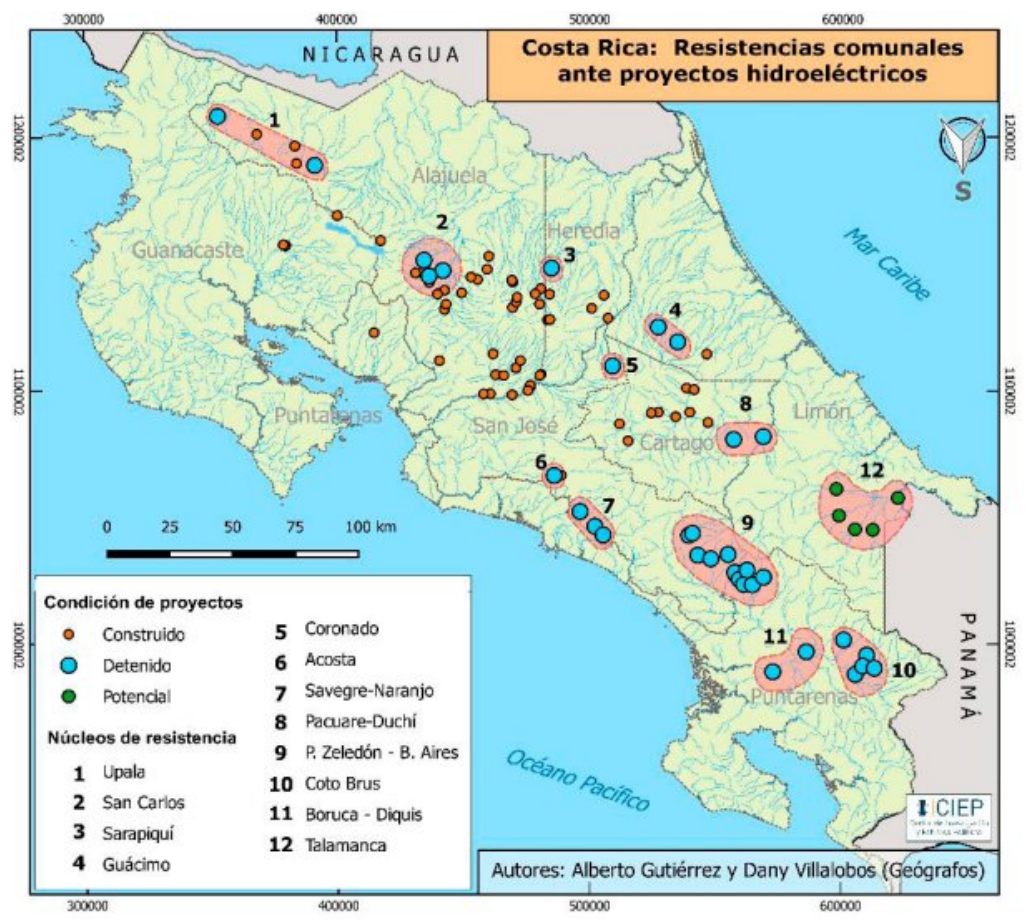

Fonte: Elaborado pelo autor, a partir de pesquisa documental e trabalho de campo realizado em 2018.

Através das lutas, as comunidades organizadas em defesa dos rios se posicionaram como atores sociais e políticos dentro de um campo que historicamente os excluiu, como é o setor elétrico. Os numerosos processos de resistência contra barragens não apenas conseguiram salvar dezenas de rios de serem represados, mas também fizeram radicais questionamentos ao modelo elétrico como um todo e os princípios que o orientam. Nesse sentido, um dos principais argumentos sobre os quais o movimento tem se apoiado é o fato de que a Costa Rica tem uma capacidade instalada de geração de energia elétrica que é o dobro da demanda máxima registrada (3.548 MW e 1.674 MW, respectivamente), motivo pelo qual é desnecessária a construção de novas barragens 
hidrelétricas. No caso da geração de eletricidade por parte de empresas privadas, a crítica por parte das organizações comunitárias e do movimento ecologista é ainda mais forte, pois, para além dos impactos sociais e ambientais nos lugares onde se instalam as barragens, esse tipo de projeto implica a transferência massiva de recursos públicos para o lucro de um pequeno e privilegiado grupo de empresas nacionais e estrangeiras. Em várias oportunidades, algumas pessoas vinculadas com o movimento em defesa dos rios já se referiram ao esquema de geração privada de eletricidade como um "sangramento" das finanças públicas.

As comunidades organizadas e o movimento ambientalista conseguiram dar visibilidade aos impactos socioambientais das barragens hidrelétricas sobre os rios, os ecossistemas, as comunidades e a sociedade em geral, posicionando esta temática como um problema público nacional. Diferente de outras épocas, nas quais em nome do "desenvolvimento" e do "progresso" se justificava qualquer tipo de impacto que as barragens pudessem provocar, as resistências comunitárias em defesa dos rios conseguiram modificar - pelo menos parcialmente - a opinião pública em relação com este assunto. A consciência social e política impulsada no fervor dessas lutas permite às pessoas enxergar com clareza que os benefícios desse tipo de obra não estão destinados para as pessoas do lugar, senão para negócios alheios. Em palavras de um cidadão da comunidade de Coronado, na luta contra o projeto hidrelétrico Río Blanco: "Não é possível que por uns quantos dólares que a empresa privada quer ganhar, destruam tudo o que as gerações do futuro têm direito a usufruir" (MONGE, 2014, p. 45 - tradução própria).

\section{Considerações finais}

O presente trabalho procurou oferecer uma perspectiva ampla do cenário atual de conflitos e lutas socioambientais na Costa Rica. Durante os últimos vinte anos, verifica-se uma exacerbação desse tipo de conflito no país, colocando em tensão a imagem oficial que o representa como um paraíso ecológico com uma realidade marcada por intensas disputas em relação ao controle, 
à apropriação e à gestão dos bens/recursos naturais e dos territórios onde estes se localizam. A mesma tendência pode observar-se na América Latina como um todo, região que tem sido objeto de uma intensificada exploração dos seus bens/recursos naturais, ao mesmo tempo em que se articulam múltiplos processos de resistência contra a exploração e a privatização dos bens comuns naturais. O trabalho pretende aportar à discussão sobre os conflitos e lutas socioambientais na América Latina (da qual existe ampla bibliografia), através da especificidade da realidade costarriquenha.

Com o propósito de visualizar esse cenário de conflitos/lutas na Costa Rica de forma mais concreta, se identificaram sete eixos de conflitividade socioambiental: (1) expansão de monoculturas de exportação, (2) enclaves turísticos e novas urbanizações, (3) superexploração d'água para projetos de irrigação, (4) infraestruturas de transporte, (5) mineração a céu aberto, (6) recuperações de terra em territórios indígenas e (7) barragens hidrelétricas. Frente à dinâmica de espoliação e privatização dos territórios e bens comuns naturais, os conflitos socioambientais se constituem como pontos de tensão em que a ordem social hegemônica não é aceita passivamente e é confrontada "desde baixo". Nesses pontos de tensão e conflito, outros mundos possíveis lutam por se afirmar, com um alto potencial emancipatório.

Finalmente, é importante mencionar que, através desse trabalho, pretende-se contribuir para a aproximação e o diálogo teórico-político entre os diferentes processos de luta na Pátria Grande, em específico entre aqueles na América Central e no Brasil, em consonância com o propósito do dossiê temático que aqui nos convoca. Imersos(as) num momento social e político que parece não oferecer alternativas emancipatórias, é fundamental prestar atenção para aquelas experiências de luta que acreditam nesses outros mundos possíveis, pois são essas experiências as que podem nos guiar para construir sociedades mais felizes, justas e em conexão com a natureza. 


\section{REFERÊNCIAS}

ALIMONDA, H. Introducción. In: (org.). Gestión ambiental y conflicto social en América Latina. Buenos Aires: CLACSO, 2008. p. $13-21$.

ÁLVAREZ, M. Proyectos hidroeléctricos privados chocan con comunidades del Pacífico Sur por uso del agua. Ambientico, Heredia, n. 237 - 238, p. $47-51,2013$.

BOTAS con machete: la cultura campesina amenazada en la zona sur de Costa Rica. Direção: Alejandro Ferlini. San José: Kioscos Socio-Ambientales de la UCR; Organización De Lucha Campesina por Nuestras Tierras del Sur, 2012. 1 vídeo (33 min, 39 seg), son., color. Disponível em: <https://www. youtube.com/watch?v=kS4MsDLUsX0>. Acesso em: 31 jul. 2019.

CARTAGENA, R. El ambientalismo y la lucha contra el combo del sector eléctrico (1998 - 2001). Revista de Ciencias Sociales, Heredia, v. 2 - 3, n. 128 - 129, p. 49 - 61, 2010.

CHACÓN, K.; MERINO, L. Veinte años de conflictividad ambiental en

Costa Rica (1994-2013): informe final. San José: Programa Estado de la Nación, 2014.

CICDE - Centro de Investigación en Cultura y Desarrollo. El territorio de Salitre: derechos, memoria y violencia (2010-2017), informe final de investigación. San José: Universidad Estatal a Distancia, 2018.

COMPOSTO, C.; NAVARRO, M. L. Claves de lectura para comprender el despojo y las luchas por los bienes comunes naturales en América Latina. In: _orgs.). Territorios en disputa. México DF: Bajo Tierra, 2014. p. $33-75$.

COSTA Rica: el precio de la piña. Bonn: Deutsche Welle, [s.f.]. 1 vídeo (25 min, 56 seg), son., color. Disponível em: <https://vimeo.com/283347135>. Acesso em: 31 jul. 2019.

DURÁN, O. Comunidades de Mesoamérica ante megaproyectos energéticos. Ambientico, Heredia, n. 226, p. 31 - 36, 2012.

EL ORO de los tontos. Direção: Pablo Ortega. San José: UMG; Public Domain Composicions, 2011. 1 vídeo (29 min, 49 seg), son., color. Disponível em: $<$ https://www.youtube.com/watch?v=gKVS1wvvEU8>. Acesso em: 31 jul. 2019.

FECON - Federación Costarricense para la Conservación de la Naturaleza. ¿Qué modelo eléctrico queremos? San José: Grupo de Trabajo Energía, 2003. 
II Foro Nacional de Comunidades Frente a la Expansión Hidroeléctrica. San José: Grupo de Trabajo Energía. 2003b.

GUTIÉRREZ, A. Líder indígena Sergio Rojas é assassinado na Costa Rica. Combate Racismo Ambiental, [on line], 20 mar. 2019. Disponível em: $<$ https://racismoambiental.net.br/2019/03/20/lider-indigena-sergiorojas-e-assassinado-na-costa-rica/>. Acesso em: 20 jul. 2019.

ICE - Instituto Costarricense de Electricidad. Índice de cobertura eléctrica 2017. San José: ICE, 2017.

LEÓN, A. Desarrollo geográfico desigual en Costa Rica: el ajuste estructural visto desde la Región Huetar Norte (1985 - 2005). San José: Editorial UCR, 2015.

LLAGUNO, J. et al. Políticas y conflictos socioambientales: el caso de la tenencia de la tierra y los monocultivos en el Caribe de Costa Rica (20062012). Revista de Ciencias Sociales, Heredia, v. 145, n. 3, p. 81 - 98, 2014.

LLAGUNO, J.; MORA, J.; PICADO, H. El mapeo colectivo: cartografiando los principales conflictos socio-ambientales y las resistencias populares en Costa Rica. San José, [2013?], no prelo.

MERLINSKY, G. Los movimientos de justicia ambiental y la defensa de lo común en América Latina: cinco tesis en elaboración. In: ALIMONDA, H., TORO, C.; MARTÍN, F. (orgs.). Ecología política latinoamericana: pensamiento crítico y horizontes emancipatorios en clave sur. v. 2. Buenos Aires: Ciccus/CLACSO, 2018. p. 241 - 264.

MONGE, L. Formarse y transformarse en la lucha social: ambientalismo costarricense y subjetividad política en la primera década del siglo XXI. 2014. 150f. Dissertação (Mestrado em Ciências Sociais) - Faculdade LatinoAmericana de Ciências Sociais, Caba, Argentina, 2014.

MORA, J. La tierra para quien la trabaja o ¿un aeropuerto en la Zona Sur? Semanario Universidad [on line], 28 jul. 2015. Disponível em: <https:// semanariouniversidad.com/opinion/la-tierra-para-quien-la-trabaja-o-unaeropuerto-en-la-zona-sur/>. Acesso em 10 jan. 2019.

PADIERNA, D. La minería y el Tratado de Libre Comercio. Dolores Padierna Luna, [on line], 6 ago. 2017. Disponível em: <http://www. dolorespadiernaluna.com/la-mineria-y-el-tratado-de-libre-comercio/>. Acesso em: 31 jul. 2019.

PEN - Programa Estado de la Nación. XX Informe Estado de la Nación en Desarrollo Humano Sostenible. San José: PEN, 2014. 
PIÑAS: el precio oculto de la fruta tropical. Londres: The Guardian, 2010. 1 vídeo (19 min, 43 seg), son., color. Disponível em: <https://www.youtube. com/watch?v=PHlLrB3toSw>. Acesso em: 31 jul. 2019.

QUEBRANDO los huevos. San José: [s.n.], 2013. 1 vídeo (32 min, 32 seg), son., color. Disponível em: <https://www.youtube.com/watch?v=pdR23l98isg>. Acesso em: 31 jul. 2019.

RAMÍREZ, A. Conflictos socioambientales y recursos hídricos en Guanacaste: una descripción desde el cambio en el estilo de desarrollo (1997-2006). Anuario de Estudios Centroamericanos, Heredia, v. 33 34, p. $359-385,2007$.

SOLÍS, M. Entre el cambio y la tradición: el fracaso de la privatización de la energía y las telecomunicaciones en Costa Rica. Revista de Ciencias Sociales, Heredia, v. 1, n. 95, p. 33 - 47, 2002.

SVAMPA, M. Consenso de los commodities y lenguajes de valoración en América Latina. Nueva Sociedad, Buenos Aires, n. 244, p. 30 - 46, 2013.

VILLALOBOS, D. Experiencias comunitarias en defensa del agua en distritos rurales de Puntarenas, Costa Rica (2005-2017). Rupturas, San José, v. 8, n. 1, p. $131-166,2018$. 